Article

\title{
Gestural Interaction and Reading Skills: A Case of Study with People with Down Syndrome
}

\author{
Pablo Vicente Torres-Carrion ${ }^{1}$, Carina González-González ${ }^{2,}$, César Bernal Bravo ${ }^{3}$, Alfonso \\ Infante-Moro ${ }^{4}$ \\ ${ }^{1}$ Department of Computer Science, Universidad Técnica Particular de Loja. Email: pvtorres@utpl.edu.ec \\ ${ }^{2}$ Department of Computer Engineering and Systems, University of La Laguna. Email: cjgonza@ull.edu.es \\ ${ }^{3}$ Department of Education, University of Almeria, Almeria, Spain. Email: cbernal@ual.es \\ ${ }^{4}$ University of Huelva, Huelva, Spain. Email: alfonso.infante@ decd.uhu.es \\ Corresponding: cjgonza@ull.edu.es
}

\begin{abstract}
People with Down syndrome present cognitive difficulties that affect their reading skills. In this study we present results about the use of gestural interaction with Kinect sensor to improve the reading skills of students with Down syndrome. Following a case of study method for small samples with disabilities, measuring different variables related to reading skills in an experimental group and in a control group. We found improvements in the visual association, visual comprehension, sequential memory, and visual integration after this stimulation in the experimental group compared to the control group. Also, we found that the number of error and delay time of interaction decrease between sessions in the experimental group.
\end{abstract}

Keywords: Down syndrome; Kinect sensor; reading skills

\section{Introduction}

People with Down syndrome (DS) can advantage from learning to read in an early age compared with those who had not this early stimulation. Through reading they can improve their spoken language and memory skills. Learners with DS learn to read in the same way of developing children. Some difficulties that DS students present in reading are related to they have a problem in hearing. So, their listening problems can affect their behavior, performance and language learning. Moreover, students with DS presents working memory difficulties, and it can also contribute to their speech and language delays [1]. Reading gives opportunities to improve these problems. Research has shown a better performance in visual memory than verbal memory of learners with DS [1, 2, 3, 4]. Their deficit can be explained by: a) hearing loss, b) speech production problems, c) poor language knowledge [5]. Some training strategies can help to fix each problem, such as: a) provide visual support; b) reduce/remove need for speech support; c) match receptive vocabulary [6, 7]. Also, research claims for a clear evidence for effective, sustainable memory training programs adapted for students with DS $[1,4,6,8]$. Usually, students with DS have a better language comprehension (understanding) than language production (talking/signing), due to their problems with word retrieval, sentence structuring and speech-motor control [6]. So, it is important to start with vocabulary that they can understand and simple sentence structures and increment the vocabulary and grammar according to their progress. Some teaching reading strategies includes typical activities such as picture matching, picture naming or picture selecting [6]. Besides, students with DS can learn about sounds associated to each letter and they can do phonetic learning activities too. Educational games about reading 
learning (typical pre-school and school age) can be used with students with DS too (i.e. PBSkids ${ }^{1}$ reading) or to working memory training (i.e. Cogmed2).

There are several specialties related with the reading teaching, such as the speech therapy, with continuous contributions of psycholinguistics [9]. Following Zubiría's theory [10], there are six levels of readings: phonetics, primary, secondary and tertiary decoding, categorical and "metatextual", leaving the first four levels as elementary and the last two as higher level. In our case, based on this theory, we have focus on secondary decoding, because it is the common level of reading in the DS population.

Reading comprehension as a cognitive process gives meaning to the relevant ideas of a text and its relation to prior knowledge, in which working memory's executive processes play a crucial role. The process of memory assessment is given through brief stimuli called 'memory reconsolidation'. Relationship between response time (velocity) and a number of identified items aiming to expose how information is maintained in short term memory and why this memory has limited capacity [11]. The memory reconsolidation allows the reactivation and modification of memories by stimuli [12]. Its strength being inversely proportional to the age of memory [13]. Taking into account this context, in this study the variables time and cognitive errors were selected as a methodological basis to measure the variation of learning between periodic lessons.

About the assessment, it allows teachers and educational system to undertake the best methodological and didactic strategies $[14,15,16]$. In students with DS, the assessment does not vary from the rest of the students in terms of measuring their achievement, measuring variables such as response time, successes and errors. However, it is important to consider the student's degree of error $[17,18]$, or the continuous feedback to the process, motivating the effort of the student, not only the achievement [15]. In this work, the assessment process has been designed and supported by technical designers and teachers taking special characteristics of DS students. One of the most important dimensions in the assessment of teaching-learning process is probably the academic performance [19]. Academic performance can be assessed by teachers according to skills and competencies proposed in curriculum planning $[15,20]$. Additionally, motivation is the key of educational process, because it initiates and directs behavior toward the achievement of a goal [19] and it promotes continuous interest in learning, reaching a level of metacognition (knowledge about knowledge). In this sense, gamification can be used as a didactic strategy for educational motivation, keeping the student's attention on achieving short-term goals and passing learning milestones in a fun way [20, 21]. These areas are the transversal axis in this work, and they have been promoted through the gestural interaction and specific didactic strategies [22].

On the other hand, the dialogue between special educational needs professionals with technological designers, evidence the growing interest in Natural Interaction (NI), and its uses in education and health $[23,24,25]$. This works presents a common vision between technological applications designers and users (teachers, students, etc.) for the specific training context for DS. The integration of NI devices and applications into teaching learning process for people with disabilities requires the design of specific didactic resources and adaptation of curricular activities and contents. So, pedagogical inclusion allows them to develop their potentialities and skills, taking into account their area of proximal development [26]. Moreover, gamification in education in combination with NI platforms can be very useful for people with some degree of motor difficulties [27, 28]. For this reason, in this work we proposed the gamified platform TANGO:H [28] which has been tested previously with people with motor difficulties, among other uses, such as to work on motivational therapies from special strategies in hospital classrooms.

This paper is organized in the following sections: first of all, we will review the related works organized by the DS reading skills stimulated by gestural interfaces. Then we describe briefly how the platform TANGO:H works and the personalization of contents and activities (exercises). After

\footnotetext{
${ }^{1}$ Web: https://pbskids.org/games/reading/
}

${ }^{2}$ Web: https://www.cogmed.com/ 
that, the experimental study is described, including methodology, research questions, hypothesis, variables and indicators, sample and educational resources adapted to TANGO:H. Then, results will be presented in the way that it can answer the hypothesis and research questions. Finally, discussion and conclusions sections will be presented.

\section{Related works}

\subsection{Reading skills of Down Syndrome students and gestural interfaces}

Reading is a process that involves deciphering of written signs and understanding their meaning, with different neurophysiological processes that can be developed at different speeds. In the case of people with DS this process and its speed is more visible, as their progress in reading comprehension is much slower than reading mechanics [29] limiting their reading to the secondary decoding level. However, there are cases called "exceptional", where has been registered a higher level reading (comprehension), highlighting the great development of phonological skills, visual and verbal work memory, which reaches a level of parallel reading comprehension (and in some cases higher) to people of their age without this pathology [30]. In this process, parents play a transcendental role, and when investigating their behavior towards this ability, it has been proved that most are very optimistic and continuously stimulate these skills at home, with extra-curricular activities [31].

People with DS have a better development of sign language for word comprehension, with a great ability to read by visual analogy, which facilitates the knowledge of the lexical elements [32]. The vocabulary and its continuous stimulation is a good predictor of reading skills [33,34], allowing to reach a degree of reading of secondary discrimination. A related study indicate that technologies improved reading therapies [35]. Taking into account the previous work, we designed didactic strategies with gestural resources to stimulate visual-motor memory in the DS population and studied the stimulation of reading abilities using gestural interaction.

Previous published research results show aspects such as reading teaching strategies [36] language and verbal memory skills (short-term memory), and predictions on language production from their understanding. It has been shown that poor phonological discrimination is not directly related to poor visual working memory in population with DS [37]. A case study showed that stimulation of the visual memory in a boy with DS compensates the deficit of verbal working memory (short-term), required for reading comprehension [39]. With this background, our didactic proposal is based on the use of a technological gamified platform TANGO:H with exercises that uses visual stimulus (text and figures) and gestural interaction [40]. So, in the following section we describe briefly the technological platform TANGO:H.

\subsection{TANGO:H}

TANgible GOal: Health (TANGO:H) is a platform for the realization of active games, from gestural interaction using the sensor Kinect (it is possible to choose the version 1 or 2). The power of TANGO:H lies in its capacity to generate exercises, i.e. it is not a static platform in which exercises or games are fully defined and integrated, but also allows the implementation of these through an editor that makes this task simple. The system interprets and executes the exercises previously created by professionals in the editor TANGO:H Designer. The interface for the end-user is an active videogame, where students performs the exercises previously created as a game, interacting with the system through body movements and gestures. The combination between editor and game modules allows the creation of a variety of exercises, personalized and adapted to the characteristic of the users.

The exercises are composed of a set of objectives (resources) that appear on the screen in a grouped way; the user must select the objectives according to several guidelines that will depend on the type of exercise:

- Physical, oriented to motor rehabilitation.

- Cognitive, to establish cognitive stimulation. 
- Classification - select certain objectives for a particular group.

- Matching - goals related to your partner.

- Classification - select in a certain logical sequence.

- Free, without specific functionality.

It can be played individually - as in our case - or collaborative / competitive with another user. Working from a gestural interface with Kinect, interaction is possible from a virtual skeleton which in version 1.0 consists of 13 points enabled for the limbs and head. As can be seen in Figure 1, the basic design for the TANGO:H platform is made from a target - contact point - which is composed of an image, color and sound. As it is shown in Figure 1, the designer is composed of 1) menu bar, 2) exercise panel, 3) objective panel, 4) available lenses panel and 5) design panel; its design is simple, and version 2 is available to perform the exercises from the web. The exercises are recorded in a .tica extension file that will be imported into the TANGO:H client application (from XML struct).

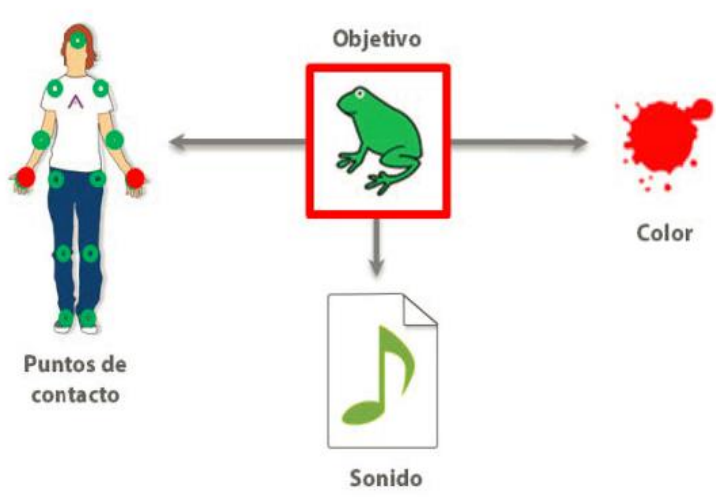

a) Objective and properties

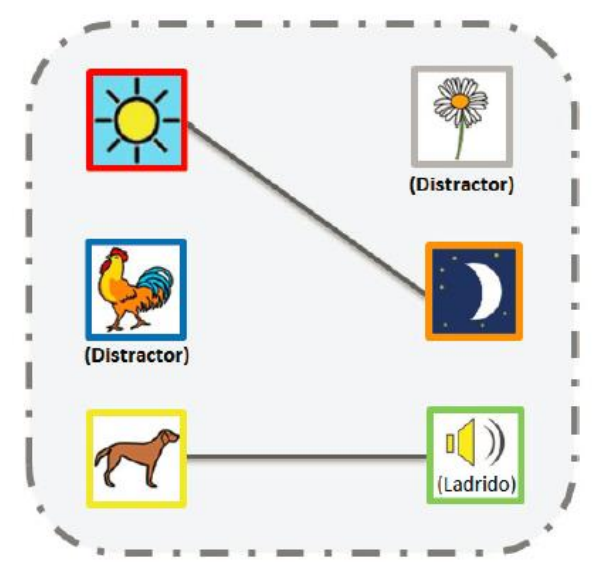

c) Matching exercise

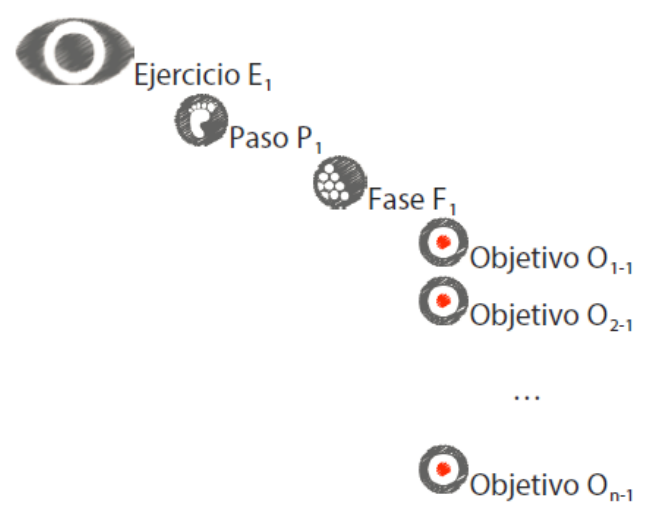

b) Structure of an exercise

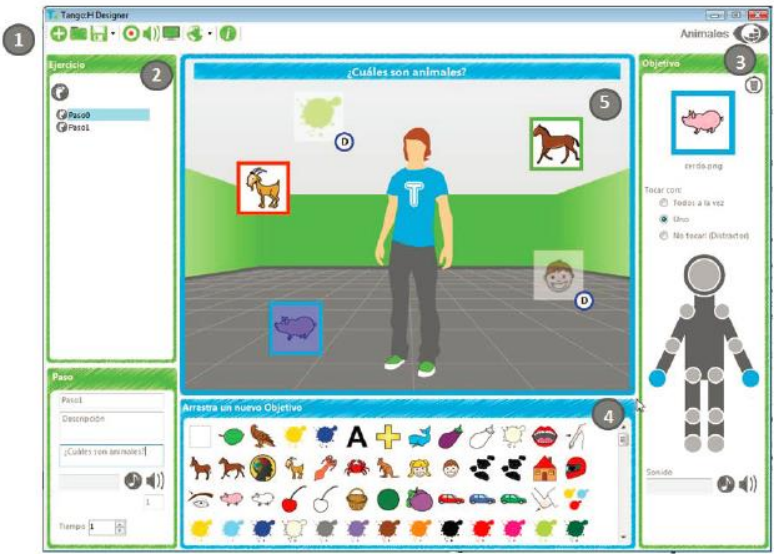

d) Main Design Window

Figure 1. TANGO H. Characteristics.

The platform has several personalization functions. User profile has some variables related with the student such as: identification (full name, user name and image), date of birth (used for the age), gender and other related with exercises, like timing and action range (Figure 2). Timing and action range allow to personalized the difficulty level of exercises to the characteristics of user. Both parameters are included in the XML definition of exercise. It may also particularize this range with a factor that is assigned to the user. All the settings for action range, both in the performance and in the user's profile, are evident in TANGO:H to the user executing the exercise, because when the user touches within the range (not necessarily in order) start counting the timing clock. This 
functionality can also create difficulty levels for exercises and users, and enables the designer to create groups of exercises that require different skills from simple to more complex. The level can be adjusted depending on the user's progress and within her/his possibilities and needs.

Also, it is possible to group users with similar characteristics and interaction needs. Each user or group can be assigned to the exercises with which they can interact. Exercises can be customized to the user characteristics at the moment of starting the interaction, assigning the corresponding scores according to the time required to comply each one of the exercises.

At the end of each sequence of exercises, a validation of the student's emotional state is performed. Students chooses among emotional emoticons (positive, negative and neutral) identifying one of it. Then a summary of the score obtained in a range of stars (from zero to five) is presented according with the time to complete exercises. Prizes, extra score or other resources can be exchanged by the student according his/her level of exercises. All this information is stored in a .log file for later analysis if it is required.

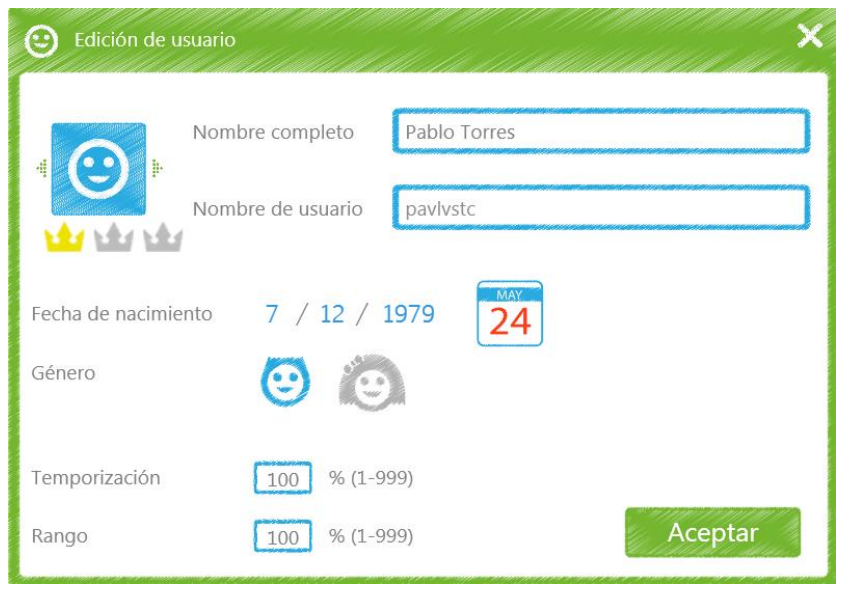

Figure 2. User profile example including the user name (real and nickname), date of birth, gender, with personalization options (temporization and range of action).

\subsection{Personalization and adaptation}

Regarding the personalization of technologies, specifically those applied to education, the NMC Horizon report 2017 K-12 Edition [41] proposes the adaptation of contents and exercises related to the student's individual profile and their learning styles, including multi-user collaborative digital environments. In this field, we found contributions oriented to the personalization and adaptation to users with cognitive and/or motor disabilities [42]. Therefore, personalization of didactic resources is fundamental for the education oriented to people with special cognitive needs [43]. So, the design of the educational resources should be developed according to the academic level and characteristics of the user. Understanding individuality, both in personal contexts and those of interaction throughout life (family, school, friends, etc.) is the key for the correct design. Personalization of learning and teaching process for students with DS needs not only to consider the motor difficulties, but several aspects of their cognitive, auditory, visual, emotional characteristics [44]. Research has shown the application videogames supported by sensor Kinect has improved the global motor, balance, body schema and spatial organization of a group of twenty children with DS [45]. Equally, through tangible interfaces DS students has achieved basic learning in computer use, learning of addition and subtraction in digital displays [46] and considerable achievements in the mechanic of reading and writing skills [47]. Despite of the existing research on DS and tangible and NI interfaces, reading comprehension has been least investigated with people with cognitive disabilities. So, reading comprehension of DS with tangible and NI interfaces has been selected as the central theme of this study. 


\section{Case of study}

\subsection{Method}

Following the recommendations of Lazar (2017) [48] on research methods for human-computer interaction (HCI) in the case of people with disabilities, we followed the method of "in-depth case study" of a small number of instances within a specific real-life context (from three to then participants). Thus, this case of study examines compare six participants divided into two groups (experimental (EG) and control (CG)). Then, three individual cases of the experimental group are analyzed to build a deep understanding, generate hypothesis, provide evidence of behaviors and other insights about the studied variables to facilitate the understanding of other cases. Although statistical analyses were not the main goal, but we tried to test the hypothesis using statistical analysis too. The main goal of this in-depth study is to assess the reading learning of the students with DS using a computer-based natural interaction environment. Thus, the research question that this study answer is: Does the stimulation through personalized educational resources from a computer-based gestural interaction environment improve the reading skills in students with Down Syndrome?

The educational exercises have been designed and developed using an educational gamified platform TANGO:H in a personalized way for each DS student. For the validation the following hypotheses have been proposed:

$h A$ : Errors of specific knowledge about stimuli with learning objects in gestural interaction environments do not vary between lessons in students with DS.

$h B$ : Response times to stimuli with didactic learning objects in environments of gestural interaction, do not vary between lessons in students with DS.

The hypotheses will be validated from the variation of the correct answers / errors and the response times to fulfill each task in the same lesson and next lessons, taking into account the theoretical basis of cognitive learning.

\subsection{Participants}

Recruitment has been carried out among the 56 members of the Down Tenerife Association from Canary Islands, Spain. A special authorization was signed by the legal representatives of each student, as well as the approval of Ethical Board of the institution. Thus, the teachers selected the sample following the inclusion criteria:

- Disability: students diagnosed with Down syndrome (Trisomy 21) and with cognitive age upper to 5 .

- Technology: students who have already worked with the TANGO:H platform for physiotherapy (for the experimental group).

- Education: students with basic reading skills.

- Communication: students capable to communicate orally.

According with Lazar [48], for research focusing on users with disabilities, it is generally acceptable to have 5-10 users with a specific disability take part in a study. Thus, this case of study was composed by six subjects with DS ( 2 females and 4 males), three who have already worked with the TANGO:H platform for physiotherapy and three who not have worked with the platform (Table 1).

Table 1. Participant characteristics.

\begin{tabular}{ccccc}
\hline ID child & Natural Age (years) & Level of education & Cognitive Age (years) & Sex \\
\hline \multicolumn{5}{c}{ Experimental Group (GE) } \\
\hline E1 & 18 & 2nd (Secondary) & 12-14 & M \\
\hline E2 & 29 & 2nd (Elementary) & 6-8 & M \\
\hline E3 & 28 & 6to (Primary) & F \\
\hline \multicolumn{7}{c}{ C1 } & Control Group (CG) & 10 & M \\
\hline
\end{tabular}




\begin{tabular}{ccccc}
\hline C2 & 23 & Inclusive classroom (Secondary) & $12-14$ & $\mathrm{M}$ \\
\hline C3 & 13 & 2do (Primary) & $6-8$ & $\mathrm{~F}$ \\
\hline
\end{tabular}

\subsection{Variables and indicators}

We measured during the experimentation and in a post test in both groups (EG and CG) the following variables: visual association, visual comprehension, sequential memory and visual integration using the ITPA instrument [49]. Moreover, in the EG we measured the variation of the time $\Delta t$ that each student requires to complete each task, as well as the variation of the number of errors committed $\Delta \mathrm{e}$; the latter were analyzed from an overview, and separating images and text, to know also which of these resources produces a better learning.
1. $\Delta t_{L 1-L 2}=t_{1}-t_{2} \quad$ Between L1 (week 1$)$ and L2 (week 2$)$
$\Delta e_{L 1-L 2}=e_{1}-e_{2}$
2. $\quad \begin{aligned} & \Delta t_{L 2-L 3}=t_{2}- \\ & t_{3}\end{aligned}$
Between L2 (week 2) and L3 (week 3)
$\Delta e_{L 2-L 3}=e_{2}-e_{3}$
Average of inter-weekly variations
3. $\overline{\Delta t_{L}}=$ $\frac{\Delta t_{L 1-L 2}+\Delta t_{L 2-L 3}}{2}$
General variation from L1 (first lesson) and L3 (final lesson)

$$
\begin{gathered}
\overline{\Delta e_{L}} \\
=\frac{\Delta e_{L 1-L 2}+\Delta e_{L 2-L 3}}{2} \\
\Delta e=e_{1}-e_{3}
\end{gathered}
$$
4. $\Delta t=t_{1}-t_{3}$

The above formulas (1-4) are applied as appropriate to obtain the following indicators:

- $\quad$ Response time $(\Delta t)$

a. Effective interaction time. It is obtained from the video recording so that the approximations in time are exact.

b. Delay time caused by device error or other external factor. This variable allows us to know the actual interaction time that the user needs to meet the objectives of the challenge in each step and session.

- Cognitive error during interaction $(\Delta \mathrm{e})$

c. Number of specific knowledge errors during each lesson (formed by the errors in exercises in each step and session).

\subsection{Procedure}

The intervention was formed by three didactic lessons, one per week. Each lesson is composed by $3 / 4$ sessions each, and it has from 5 to 15 exercises (sequence, classification and / or pairing) (Figure 3). The exercises have been designed and programmed according to the characteristics and skills of each participant. Thus, all the exercises have been designed in a personalized way for each student in TANGO:H Designer, having as reference the individual workbooks designed in a personalized way by the teachers, as well as the learning objectives and competences foreseen for this lesson within the academic cycle planning. The least invasive intervention was performed, proceeding in such a way that there is no change in the students' daily activities, being therefore a non-invasive study for the academic and general training activities that they perform within the Down Tenerife Association.

The mediator role was carried by the teacher with the researcher's support. The resources were applied in a repetitive way: the same resources per student in all the lessons in three continuous weeks, according to the availability of time and the own advances of each student. A structured observation was made by the researcher and the classroom teacher, to have a source of subjective comparison of learning based on the teacher's experience. It is also done recording the entire video intervention with two digital cameras, located behind and in front of the individual, for the validation of interaction times. 


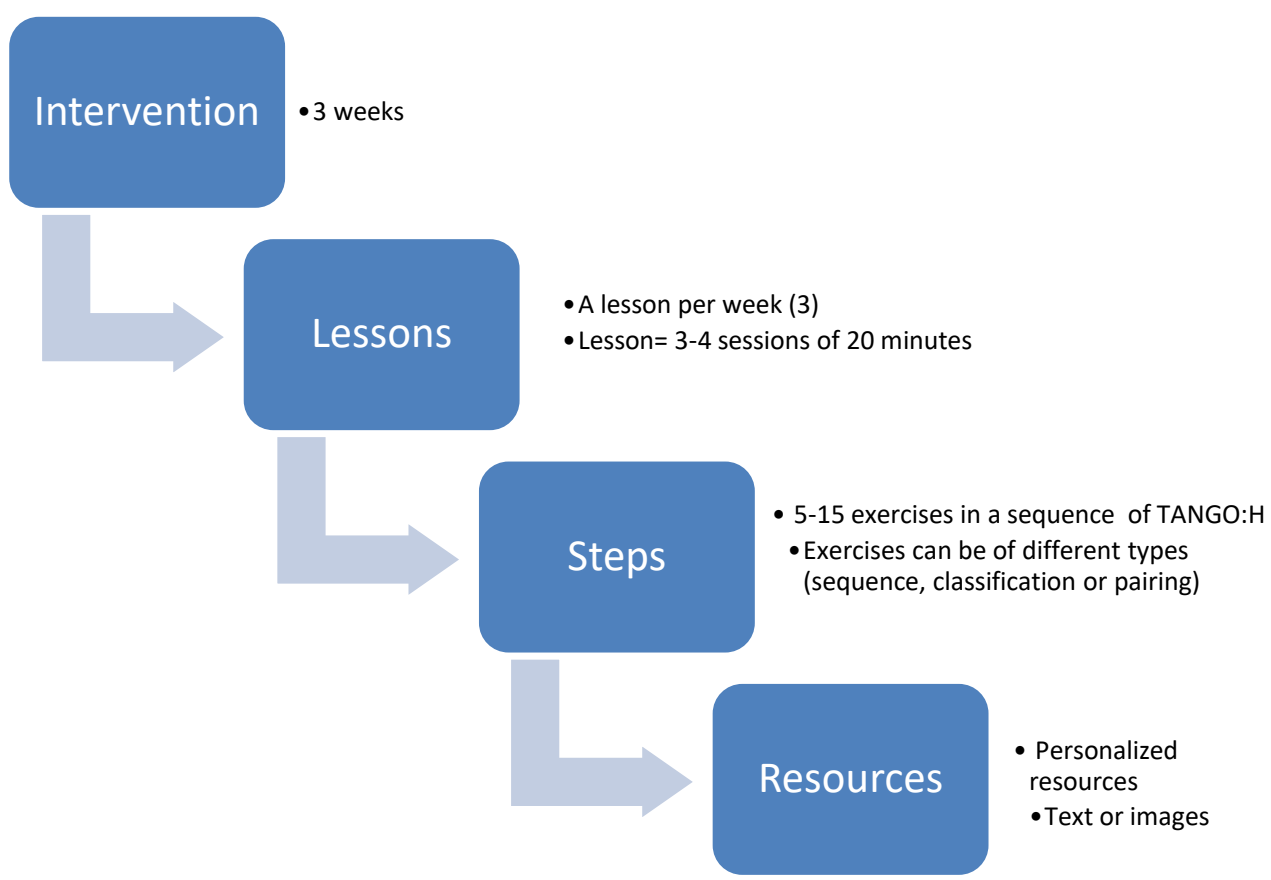

Figure 3. Structure of intervention.

\subsection{Resources designed and adapted in TANGO:H}

The didactic resources have been personalized according to the information shared by the teachers of the ATT21, from the Language and Speech therapy workshop. As the objectives within the TANGO:H platform are image files, both graphics and text were saved in image format, following workbook parameters. Different exercises were prepared and repeated during the weekly lessons. The lessons were planned according to motor and cognitive abilities of each student, as shown in Table 2.

Table 2. Example of an exercise in TANGO:H.

\begin{tabular}{|l|l|}
\hline \multicolumn{2}{|c|}{ Exercise E1_S1: Relate direct syllabic groups $k}$. \\
\hline Exercise 1 & Title: E1_S1 \\
The user must relate the two-letter syllable & Exercise Type: Cognitive Matching \\
to the three-syllable (5 steps). Then, to find & Game Mode: Single Guided \\
their relationship with the pictures by & Number of steps: 15 \\
doing a practice from the identification and & Number of achievable goals: 30 \\
pronunciation (5 steps). Finally the user & Number of distractors: 45 \\
must relate the syllable to the word, which & Maximum duration for maximum score: 90 sec. \\
is the same as the previous image (5 steps) & Maximum points: 150 \\
& Minimum points: 30 \\
& Special rules: A previous orientation of the exercise is made, and \\
& is guided to the player, especially when he has greater difficulties \\
& to avoid frustration. \\
\hline
\end{tabular}




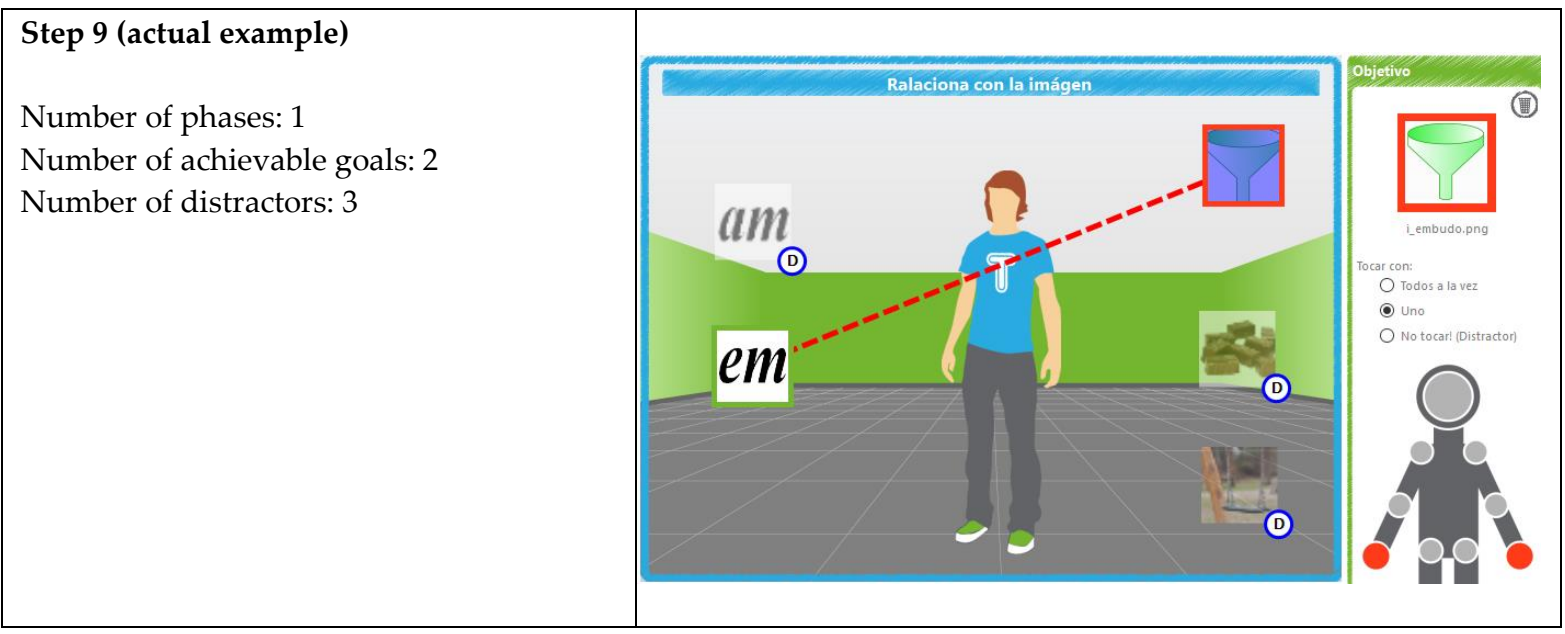

\subsection{Results}

A descriptive analysis has been carried out based on measures of central tendency (mean and standard deviation) about the variables (visual association, visual comprehension, sequential memory and visual integration), comparing the experimental and the control group. Table 3 present the results obtained in SPSS.

Table 3. Comparison of the paired differences of variables by groups (experimental and control) in the post test.

\begin{tabular}{lccccc}
\hline Variable & Groups & N & Mean & $\begin{array}{l}\text { Std. } \\
\text { Deviation }\end{array}$ & Std. Error Mean \\
\hline Visual Comprehension Post & Experimental & 3 & $\mathbf{2 2 , 0 0}$ & 3,000 & 1,732 \\
& Control & 3 & 21,00 & 0,000 & 0,000 \\
& & & $\mathbf{1 3 , 6 7}$ & 4,726 & 2,728 \\
Sequential Memory & Experimental & 3 & & & \\
Visual-Motor Post & Control & 3 & 8,67 & 2,309 & 1,333 \\
Visual Association Post & Experimental & 3 & $\mathbf{2 7 , 6 7}$ & 3,512 & 2,028 \\
& Control & 3 & 17,67 & 2,517 & 1,453 \\
Visual Integration Post & Experimental & 3 & $\mathbf{1 9 , 0 0}$ & 4,359 & 2,517 \\
& Control & 3 & 13,33 & 1,528 & 0,882 \\
\hline
\end{tabular}

Regarding the analysis on the EG, the response time and relationship errors made during the entire interaction was analyzed individually as well as comparing the data of each step and session during three lessons (Figure 3). The observed time and errors caused by the Kinect sensor has been omitted in the analysis to avoid distortion of the data. The interaction time has been maintained until the correct response is presented, omitting particular cases as in E1-Lesson 3-Sessions 1 and 2, where a slight increase in response times can be seen in Figure 4. 


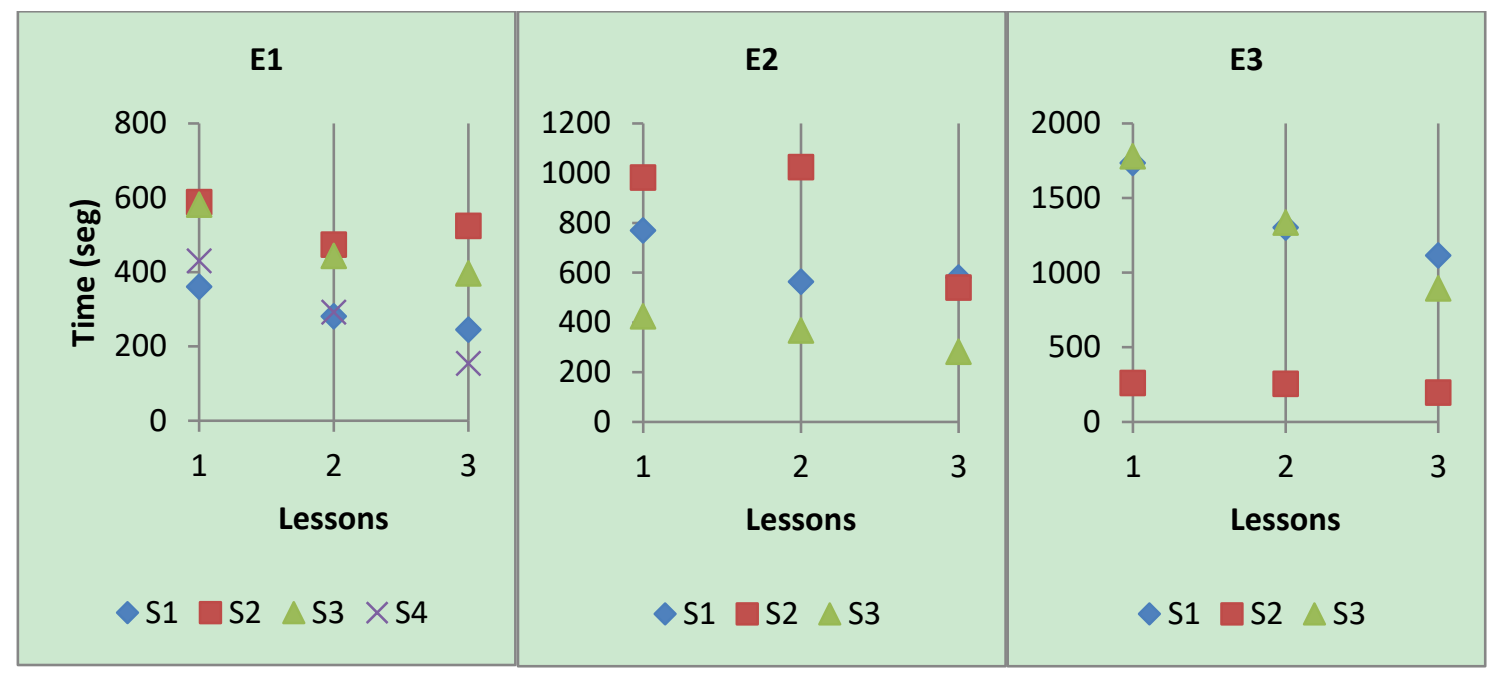

a) Response times per participant, lesson and session.
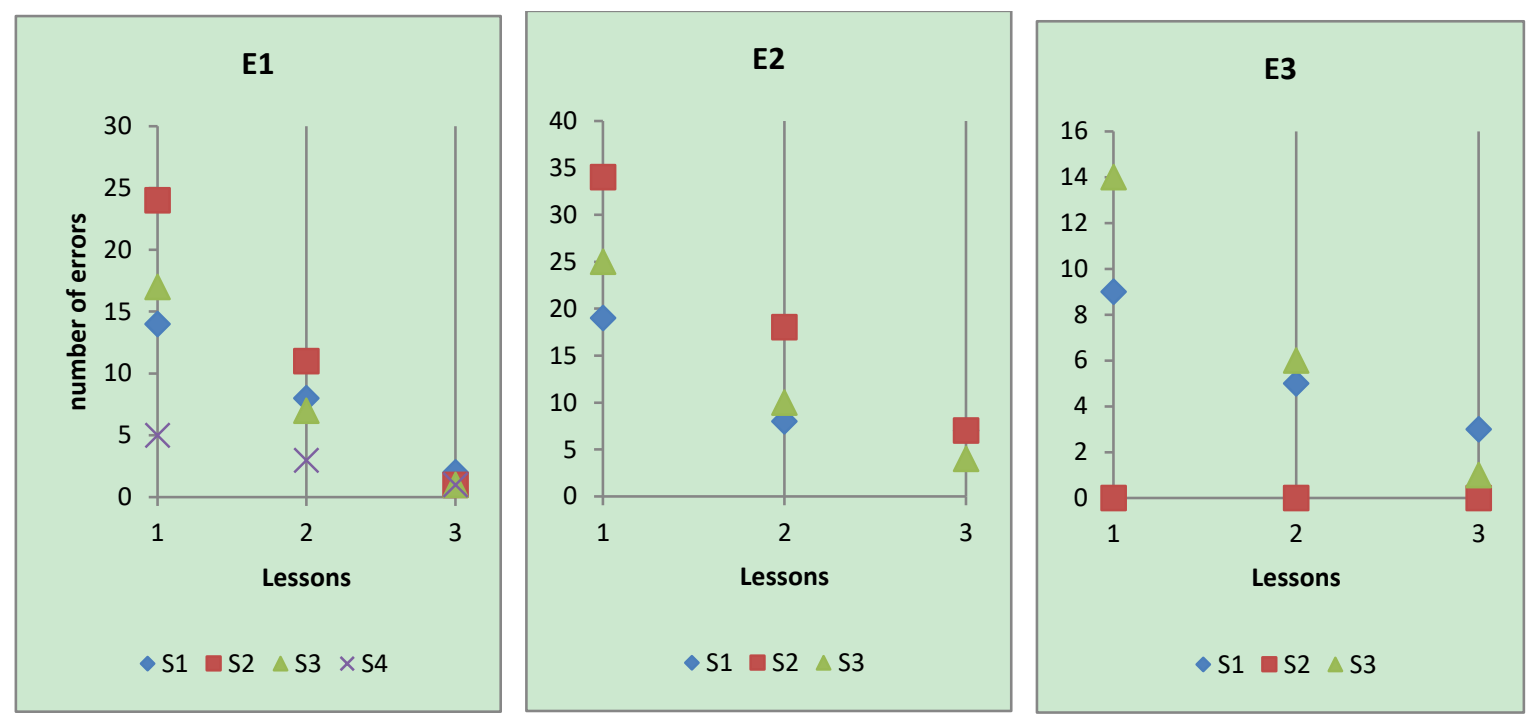

a) Errors in the interaction (lesson and session) per participant.

Figure 4. Variations of indicators of interaction of each participant.

Interaction times are affected by errors of the Kinect sensor, or by not correctly complying with the specifications of each step in the interaction resources. As can be seen in Figures 5 and 6, these errors are greater at the beginning of each lesson, in session 1 , and they are decreasing continuously as the sessions of each lesson progress (Table 4). These errors have a direct relationship with the user, and their abilities for gestural interaction with Kinect, since in each case an independent curve is presented per user, without having a relation between one user and another. Thus, the experience and user interaction skills directly influence the performance, if the measurement of this is sustained in the time required to comply with a learning activity. 


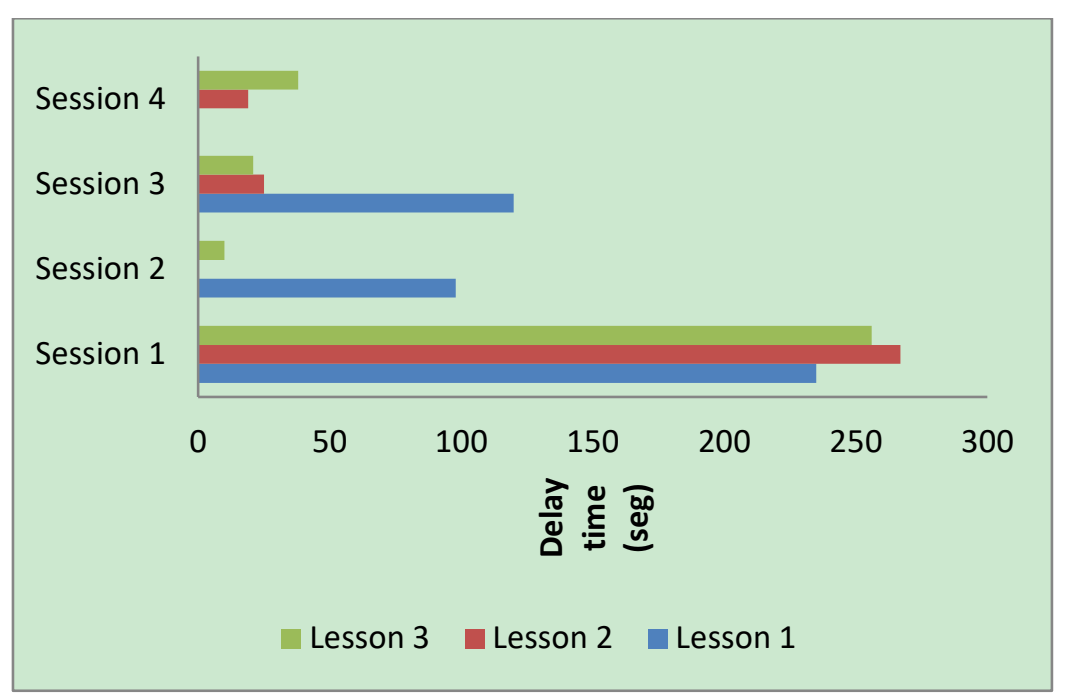

Figure 5. Total delay time in interaction ordered by resources and lessons of sessions.

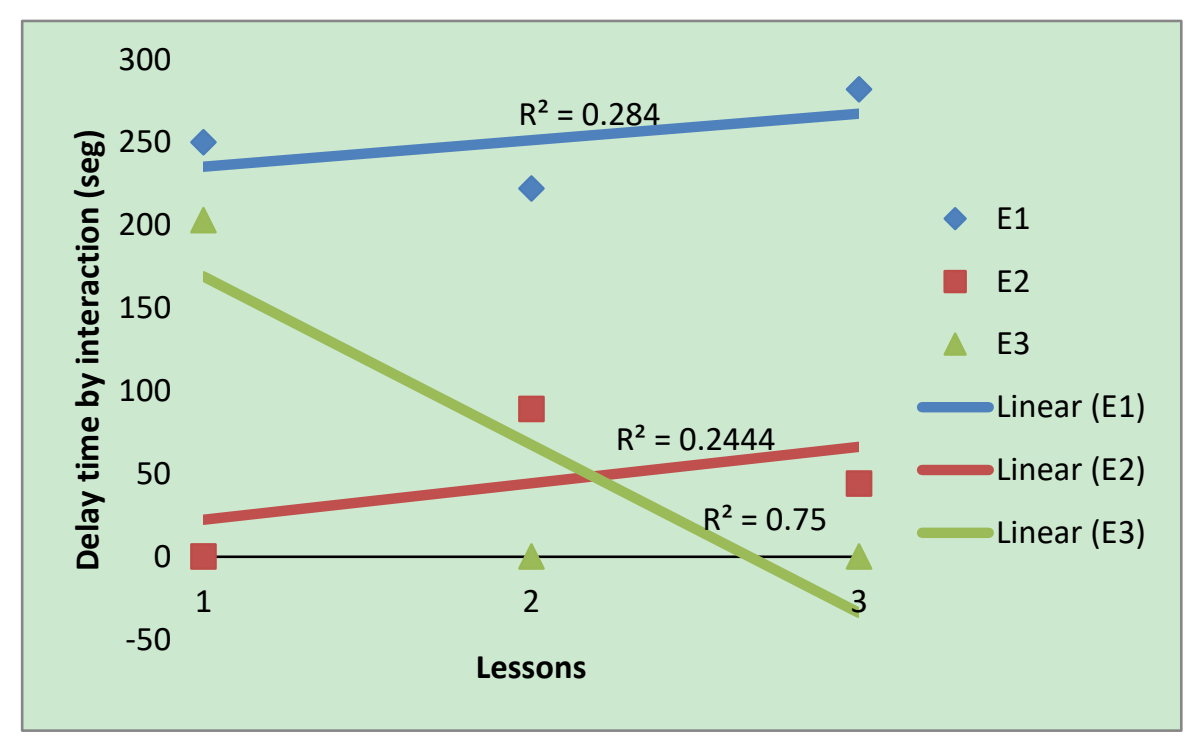

Figure 6. Delay time caused by interaction organized by user and lessons.

Table 4. Time in sessions and lessons of EG.

\begin{tabular}{|c|c|c|c|c|c|c|c|c|}
\hline & & L1 & L2 & L3 & $\operatorname{dif} 1$ & $\operatorname{dif} 2$ & $\begin{array}{c}\text { dif } \\
\text { media }\end{array}$ & $\operatorname{dif} t$ \\
\hline \multirow{4}{*}{ E1 } & S1 & 361 & 281 & 245 & 80,0 & 36,0 & 58,0 & 116,0 \\
\hline & S2 & 588 & 474 & 524 & 114,0 & $-50,0$ & 32,0 & 64,0 \\
\hline & S3 & 582 & 444 & 397 & 138,0 & 47,0 & 92,5 & 185,0 \\
\hline & S4 & 430 & 292 & 154 & 138,0 & 138,0 & 138,0 & 276,0 \\
\hline \multirow{3}{*}{ E2 } & S1 & 769 & 564 & 580 & 205,0 & $-16,0$ & 94,5 & 189,0 \\
\hline & S2 & 982 & 1024 & 540 & $-42,0$ & 484,0 & 221,0 & 442,0 \\
\hline & S3 & 425 & 367 & 282 & 58,0 & 85,0 & 71,5 & 143,0 \\
\hline \multirow{3}{*}{ E3 } & S1 & 1735 & 1303 & 1114 & 432,0 & 189,0 & 310,5 & 621,0 \\
\hline & S2 & 261 & 254 & 196 & 7,0 & 58,0 & 32,5 & 65,0 \\
\hline & S3 & 1781 & 1335 & 894 & 446,0 & 441,0 & 443,5 & 887,0 \\
\hline
\end{tabular}

Applying the t-Student statistic we found that variation in time is significant, in the first two sessions as in the inter-session media. Only the difference between session 2 and 3 has not been significant (see Table 5). 
Table 5. Time variation between lessons and session in the studied participants.

\begin{tabular}{cccccc}
\hline & $\begin{array}{c}\text { Media } \\
\text { in seconds }\end{array}$ & Standard deviation & $\begin{array}{c}\text { Typical error } \\
\text { Media }\end{array}$ & t-Student & $\begin{array}{c}\mathrm{t} \\
(0,01 ; 9)\end{array}$ \\
\hline$\Delta t_{L 1-2}$ & 157,6000 & 163,9269 & 51,8383 & $\mathbf{3 , 0 4 0 2}$ & 2,8214 \\
$\Delta t_{L 2-3}$ & 141,2000 & 182,8714 & 57,8290 & 2,4417 & 2,8214 \\
$\Delta t_{L}$ & 149,4000 & 135,7395 & 42,9246 & $\mathbf{3 , 4 8 0 5}$ & 2,8214 \\
$\Delta t$ & 298,8000 & 271,4790 & 85,8492 & $\mathbf{3 , 4 8 0 5}$ & 2,8214 \\
\hline
\end{tabular}

Also, we have worked with the errors that each student has made during each session and lesson (see Table 6). The results showed a significant difference of results between sessions with a confidence level $99 \%$ (Table 7). Only between the second and third session the variation does not exceed this degree of confidence.

Table 6. Number of errors by sessions and lessons during the interaction of EG.

\begin{tabular}{rcccrrrrr} 
& & & & \multicolumn{2}{c}{ dif 1 } & dif 2 & \multicolumn{1}{c}{ dif t } \\
& & L1 & L2 & L3 & \multicolumn{1}{c}{ (L1-L2) } & (L2-L3) & dif media & (L1-L3) \\
\hline \multirow{5}{*}{ E1 } & S1 & 14 & 8 & 12 & 6 & -4 & 1 & 2 \\
& S2 & 24 & 11 & 1 & 13 & 10 & 11,5 & 23 \\
& S3 & 17 & 7 & 1 & 10 & 6 & 8 & 16 \\
& S4 & 5 & 3 & 1 & 2 & 2 & 2 & 4 \\
\hline \multirow{3}{*}{ E2 } & S1 & 19 & 8 & 7 & 11 & 1 & 6 & 12 \\
& S2 & 34 & 18 & 7 & 16 & 11 & 13,5 & 27 \\
& S3 & 25 & 10 & 4 & 15 & 6 & 10,5 & 21 \\
\hline \multirow{2}{*}{ E3 } & S1 & 9 & 5 & 3 & 4 & 2 & 3 & 6 \\
& S2 & 0 & 0 & 0 & 0 & 0 & 0 & 0 \\
& S3 & 14 & 6 & 1 & 8 & 5 & 6,5 & 13 \\
\hline
\end{tabular}

Table 7. t-Student statistic of variation of relationship (comprehension) errors between lessons and session.

\begin{tabular}{cccccr}
\hline & $\begin{array}{c}\text { Media } \\
\text { in seconds }\end{array}$ & Standard deviation & $\begin{array}{c}\text { Typical error } \\
\text { Media }\end{array}$ & t-Student & $\begin{array}{c}\text { T } \\
(0,01 ; 9)\end{array}$ \\
\hline$\Delta e_{L 1}$ & 8,5000 & 5,4620 & 1,7272 & $\mathbf{4 , 9 2 1 2}$ & 2,8214 \\
$\Delta e_{L 2}$ & 3,9000 & 4,6056 & 1,4564 & 2,6778 & 2,8214 \\
$\Delta e_{L}$ & 6,2000 & 4,6738 & 1,4780 & $\mathbf{4 , 1 9 4 9}$ & 2,8214 \\
$\Delta e$ & 12,4000 & 9,3476 & 2,9560 & $\mathbf{4 , 1 9 4 9}$ & 2,8214 \\
\hline
\end{tabular}

\section{Discussion}

The results show that the variables visual association $(E G=22,00 ; C G=21,00)$, visual comprehension ( $E G=13,67 ; C G=8,67)$, sequential memory $(E G=27,67 ; C G=17,67)$, and visual integration (EG=19,00; $C G=13,33$ ) improved after stimulation with playful teaching strategies from an environment of computer gestural interaction in students with Down Syndrome. Also, the results show a significant change in the time variables $\Delta t$ and cognitive errors $\Delta \mathrm{e}$, from which the null hypotheses: $\mathrm{hA}_{0}$ and $\mathrm{hB} \mathrm{B}_{0}$ are rejected. Response times, such as the number of errors that students have made in relation to the first lesson and between consecutive lessons, have been reduced in significant percentages according to the visible t-Student $(n=9$, confidence level 0.01) visible in tables 3 and 4 . In the case of the $\Delta t$, the difference is greater between the first two lessons (3.0402>2.8214), decreasing between the second and third. However, at the general level between the beginning and the end of the intervention, the statistically significant difference $(3.4805>2.8247)$ is maintained. For $\Delta \mathrm{e}$, the trend is similar, decreasing greatly between the first and second lessons (4.9212> 2.8214), the difference between the second and third lessons decreases, but is still significant between the first and last lessons $(4,1949,2.8214)$. This difference could be even greater if we directly discriminate the Session 2 of E3, since it denotes a domain of the topic from the first session having a margin of error $=0$.

With these results, it is possible to answer the research question Q1 about if the gestural interaction improves the reading skills in people with Down syndrome. The answer is supported by 
the significant statistical variation $(99 \%)$ of the variables $\Delta \mathrm{e}$ and $\Delta \mathrm{t}$, with a progressive reduction between continuous lessons to stimuli with didactic objects of learning in environments of gestural interaction, which results are significant improvements in the measured variables. The periodic stimulation (weekly in our case) and the results, are part of the theoretical representation of Morgado (2005) [50], which exposes the reconsolidation of memory from the reactivation and stimuli modification. Then, the variables related to reading skills (visual association, visual comprehension, sequential memory, and visual integration), have improved in the EG compared to the CG.

The didactic strategies promoted from an environment of natural interaction through gestures are emerging pedagogical tools, which not only refers to the education of people with cognitive and motor disabilities. For this reason, they can be extended to a global context of application in all educational institutions, complemented by augmented and virtual reality technology. The above does not neglect other didactic strategies highly valued by pedagogues, but on the contrary, complements and strengthens them. Also referring to the need to consider the particular characteristics of the user through personalized exercises. Results are also corroborated, which from reading through visual analogy improves the knowledge of lexical elements, predictors of reading skills. Reading comprehension in DS is slower than reading mechanics.

The experimentation has been developed by a stimulation process of 3 lessons (one per week). This has allowed us to measure the individual variation of each individual between lessons, and in a general way between the first and last lesson to know the actual variation after the experimentation. The longitudinal method is common in small research groups, case-centered research groups in which a specific behavior is monitored, or variation on a stimulus in a timeline. It promotes a process of non-invasive interaction, with minimal variation in the daily work agenda, which limits the students' working time to few didactic lessons. The opening of the authorities, legal representatives and professionals of the Down Tenerife Association, allowed the adaptation of the spaces of interaction according to the Kinect requirements. TANGO:H Designer facilitated the development of didactic resources of interaction from the conventional workbooks, personalized for each student. The resources designed and the didactic strategies are based on a gestural interaction with image and text resources, which stimulate visual spatial working memory, from which better learning has been achieved in people with Down syndrome. According to results the visual stimulation applied allows significant learning.

The particular form of interaction that was presented during lesson 3 with E1 and E2 is worthy of mention as a complementary contribution. Besides, their behavior has been assessed qualitatively through descriptive observation. It is visible that the student has fun during the interaction and that he has a mastery of the subject. This behavior corresponds to metalinguistic abilities, which implies not only the ability to use language, but also to think about it, play, express, analyze it componential, make judgments (phonology, axis, semantics, pragmatics). Thinking metalinguistic is present in the act of joking with words, separating what is said of meaning.

Finally, we believe and recommend to stimulate the didactic work in the classroom from environments of gestural interaction, as one of the complementary work strategies to achieve the reading comprehension skills. Since it is not an inferential study, and being an emerging research area. Therefore, it is necessary to continue the study with a broader population and considering other variables, which relate other aspects of learning and various areas of science.

In the following section main conclusions, limitations of this study and further work is presented.

\section{Conclusions}

In this paper we described a study about the improvement of visual motor memory in DS students using a gestural interaction and personalized educational resources. Highlight the following main findings:

1. Interaction times in learning spaces based on gesture interaction devices and personalized resources for students with DS decrease between lessons on the same thematic contents; this implies improvement of the reading skills. 
2. Stimulating visual-motor memory from gestural interaction environments and personalized resources is a didactic strategy that improves reading skills significantly in students with DS.

3. Students with DS exhibit characteristics of higher order learning, reflected in metalinguistic skills, not obtained in previous studies with periodic stimulation of such a short time. Students joked with the answers by discriminating the correct ones and deliberately mentioning the errors.

4. Users learn quickly to interact with didactical resources from gestural interaction platform; this is evidenced by the continuous decrease of non-cognitive errors presented in the initial sessions. They also tend to disappear as the process of experimentation progresses, with improvements in their gestural interaction skills.

As limitations of the study, we found the possibility of having a specific academic history of the learning of the reading of each one of the participants of the study. This would allow us to make a linear comparison between the advances of the traditional learning in relation to the reached in this experimental period. It would be of great interest also to have other physiological and sensorial variables to know the variation that individual is having during the stimulation processes with the TANGO:H gestural interaction. But, during the intervention some errors with the gestural platform caused by environmental or limiting situations of the sensors, directly affect the behavior of the student in the specific session. Another factor to consider is that the experimental process is not part of the general curricular planning of the Down Tenerife Association. Thus, it has been proposed to the directors to consider the option of maintaining a continuous stimulation laboratory, as part of the annual academic planning. So, all staff of the institution can be an integral part of this process, and students can have more learning spaces. As further works, we will add to the interaction platform the function for automatically customize learning resources based on the interaction skills that each student, as well as the emotional state that her/his shows during the interaction.

Acknowledgments: The authors want to thank to Nuria Reyes-Alonso and Selene Hernández-Morales for their active help in this study, developed under their supervision in the Down Tenerife Association; also, want to thank to Lorenzo Moreno Ruiz, the children and families of this Association for their participation in the study. Besides, the authors thanks to "Fundación Carolina" for their financial support to this work.

Author Contributions: "Pablo V. Torres-Carrión and Carina S. González-González conceived and designed the experiments; Pablo Torres-Carrión performed the experiments and analyzed the data; Carina González wrote the paper; Cesar Bernal-Bravo and Alfonso Infante-Moro edited and reviewed the paper.

Conflicts of Interest: The authors declare no conflict of interest. The founding sponsors had no role in the design of the study; in the collection, analyses, or interpretation of data; in the writing of the manuscript, and in the decision to publish the results.

\section{References}

[1] Bennett, S. J., Holmes, J., \& Buckley, S. (2013). Computerized memory training leads to sustained improvement in visuospatial short-term memory skills in children with Down syndrome. American journal on intellectual and developmental disabilities, 118(3), 179-192.

[2] Chapman, R. S., Seung, H., Schwartz, S. E., \& Bird, E. K. (2000). Predicting language production in children and adolescents with Down syndrome: the role of comprehension. Journal of Speech, Language \& Hearing Research, 43(2), 340-350. Retrieved from http://search.ebscohost.com/login.aspx?direct=true\&db=ccm\&AN=2000050630\&lang=es\&site=ehost-live

[3] Hick, R. F., Botting, N., \& Conti-Ramsden, G. (2005). Short-term memory and vocabulary development in children with Down syndrome and children with specific language impairment. Developmental Medicine and Child Neurology, 47(8), 532-538.

[4] Lanfranchi, S., Pulina, F., Carretti, B., \& Mammarella, I. C. (2017). Training spatial-simultaneous working memory in individuals with Down syndrome. Research in developmental disabilities, 64, 118-129. 
[5] Al-Yaari, S. A. S. (2013). Using audio-visual aids and computer-assisted language instruction (CALI) to overcome learning difficulties of speaking in students of special needs. Journal for the Study of English Linguistics, 1(2), 231-255.

[6] Hughes, T. A., \& Fredrick, L. D. (2006). Teaching vocabulary with students with learning disabilities using classwide peer tutoring and constant time delay. Journal of Behavioral Education, 15(1), 1-23.

[7] Majerus, S., \& Barisnikov, K. (2018). Verbal short-term memory shows a specific association with receptive but not productive vocabulary measures in Down syndrome. Journal of Intellectual Disability Research, 62(1), 10 20.

[8] Buckley, S., \& Bird, G. (1993). Teaching children with Down syndrome to read. Down syndrome Research and practice, 1(1), 34-39.

[9] Calvo, E. M. M., Muñoz, L. M. M., García González, M. C., \& Labrada, L. A. G. (2013). Reading comprehension of scientific texts in the teaching-learning process. Humanidades Médicas, 13(3), 772-804.

[10] De Zubiría Samper, Miguel. Teoría de las Seis Lecturas. Tomo II, Fundación Alberto Merani - Fondo de Publicaciones Bernardo Herrera Merino, Santa Fe de Bogotá, 2000.

[11] Vergauwe, E., \& Cowan, N. (2014). A common short-term memory retrieval rate may describe many cognitive procedures. Frontiers in Human Neuroscience, 8, 126. https://doi.org/10.3389/fnhum.2014.00126

[12] Morgado, I. (2005). The psychobiology of learning and memory fundamentals and recent advances. Revista de Neurología, 40(5), 289-297Morgado, 2005.

[13] Suzuki, A., Josselyn, S. a, Frankland, P. W., Masushige, S., Silva, A. J., \& Kida, S. (2004). Memory reconsolidation and extinction have distinct temporal and biochemical signatures. The Journal of Neuroscience : The Official Journal of the Society for Neuroscience, 24(20), 4787-4795. https://doi.org/10.1523/JNEUROSCI.549103.2004

[14] Abascal Fernández, J., \& Ríos Carrasco, M. (1998). Modelo constructivista-contextual del aprendizaje. Vygotski y Bruner. Psicología de La Educación Y Del Desarrollo, 401-422.

[15] Ferreiro, R. (2012). Cómo ser Mejor Maestro: el método ELI (Vol. 3ra). Mexico: Trillas.

[16] Lidz, C. S., \& Gindis, B. (2003). Dynamic Assesment of the evolving Cognitive Functions in Children. Vygostky's Educational Theory in Cultural Context, 99-116.

[17] Overton, T. (2000). Assessment in special education: an applied approach (Vol. 3rd). Upper Saddle River: Prentice-Hall. Retrieved from http://trove.nla.gov.au/work/19949874?selectedversion=NBD7950758

[18] Visu-Petra, L., Benga, O., Tincas, I., \& Miclea, M. (2007). Visual-spatial processing in children and adolescents with Down's syndrome: a computerized assessment of memory skills. Journal of Intellectual Disability Research, 51(12), 942-952 11p. https://doi.org/10.1111/j.1365-2788.2007.01002.x

[19] Navarro, R. E. (2003). El rendimiento académico: concepto, investigación y desarrollo. REICE - Revista Electrónica Iberoamericana Sobre Calidad, Eficacia Y Cambio En Educación, 1(2), 1-15. https://doi.org/2152

[20] Kapp, K. M. (2012). The Gamification of Learning and Instruction: Game-Based Methods and Strategies for Training and Education. Hoboken: Pfeiffer [Imprint].

[21] González-González, C. S., Toledo-Delgado, P., Padrón, M., Santos, E., \& Cairos, M. (2013). Including gamification techniques in the design of Tango: H Platform. J. Teknol, 63, 77-84.

[22] Bossavit, B., \& Pina, A. (2014). Designing Educational Tools, Based on Body Interaction, for Children with Special Needs Who Present Different Motor Skills. In 2014 International Conference on Interactive Technologies and Games (pp. 63-70). IEEE. Retrieved from http://ieeexplore.ieee.org/lpdocs/epic03/wrapper.htm?arnumber=6990192

[23] Hsu, H. J. (2011). The Potential of Kinect in Education. INTERNATIONAL Journal of Information and Education Technology, 1(5), 365.

[24] Boutsika, E. (2014). Kinect in education: A proposal for children with autism. Procedia Computer Science, 27, 123-129.

[25] Dehkordi, S. R., Ismail, M., \& Diah, N. M. (2018). A Review of Kinect Computing Research in Education and Rehabilitation. International Journal of Engineering \& Technology, 7(3.15), 19-23.

[26] Ruijs, N. M., \& Peetsma, T. T. D. (2009). Effects of inclusion on students with and without special educational needs reviewed. Educational Research Review, 4(2), 67-79. https://doi.org/10.1016/j.edurev.2009.02.002

[27] Kourakli, M., Altanis, I., Retalis, S., Boloudakis, M., Zbainos, D., \& Antonopoulou, K. (2017). Towards the improvement of the cognitive, motoric and academic skills of students with special educational needs using Kinect learning games. International Journal of Child-Computer Interaction, 11, 28-39. 
[28] González, C., Toledo, P., \& Padrón, M. (2013). TANGO: H: Creating Active Educational Games for Hospitalized Children. Management Intelligent .... Retrieved from http://link.springer.com/chapter/10.1007/978-3-31900569-0_17

[29] Troncoso, M. V., \& Flórez, J. (2011). Comprensión en la lectura de las personas con síndrome de Down. Revista Síndrome de Down: Revista española de investigación e información sobre el Síndrome de Down. Fundación Síndrome de Down de Cantabria.

[30] Groen, M. A., Laws, G., Nation, K., \& Bishop, D. V. (2006). A case of exceptional reading accuracy in a child with Down syndrome: Underlying skills and the relation to reading comprehension. Cognitive Neuropsychology, 23(8), 1190-1214.

[31] Ricci, L., \& Osipova, A. (2012). Visions for literacy: parents' aspirations for reading in children with Down syndrome. British Journal of Special Education, 39(3), 123-129. https://doi.org/10.1111/j.14678578.2012.00547.x

[32] Laws, G., Brown, H., \& Main, E. (2015). Reading comprehension in children with Down syndrome. Reading and Writing, 29(1), 21-45. https://doi.org/10.1007/s11145-015-9578-8

[33] Caselli, M. C., Vicari, S., Longobardi, E., Lami, L., Pizzoli, C., \& Stella, G. (1998). Gestures and Words in Early Development of Children With Down Syndrome. Journal of Speech Language and Hearing Research, 41(5), 1125. https://doi.org/10.1044/jslhr.4105.1125

[34] Næss, K. A. B., Melby-Lervåg, M., Hulme, C., \& Lyster, S. A. H. (2012). Reading skills in children with Down syndrome: A meta-analytic review. Research in developmental disabilities, 33(2), 737-747.

[35] Felix, V. G., Mena, L. J., Ostos, R., \& Maestre, G. E. (2017). A pilot study of the use of emerging computer technologies to improve the effectiveness of reading and writing therapies in children with Down syndrome. British Journal of Educational Technology, 48(2), 611-624.

[36] Steele, A., Scerif, G., Cornish, K., \& Karmiloff-Smith, A. (2013). Learning to read in Williams syndrome and Down syndrome: Syndrome-specific precursors and developmental trajectories. Journal of Child Psychology and Psychiatry, 54(7), 754-762.

[37] Muro Haro, B., Santana Mamcilla, P., \& García Ruiz, M. (2012). Uso de interfaces tangibles en la enseñanza de lectura a niños con síndrome de Down. El Hombre Y La Máquina, 19-25. Retrieved from http://www.redalyc.org/articulo.oa?id=47824590004

[38] Chapman, R. S., Seung, H. K., Schwartz, S. E., \& Bird, E. K. R. (2000). Predicting language production in children and adolescents with Down syndrome: The role of comprehension. Journal of Speech, Language, and Hearing Research, 43(2), 340-350.

[39] Purser, H. R., \& Jarrold, C. (2013). Poor phonemic discrimination does not underlie poor verbal short-term memory in Down syndrome. Journal of experimental child psychology, 115(1), 1-15.

[40] Lecas, J. F., Mazaud, A. M., Reibel, E., \& Rey, A. (2011). Using visual strategies to support verbal comprehension in an adolescent with Down syndrome. Child Language Teaching and Therapy, 27(1), 84-96.

[41] Freeman, A., Becker, S. A., \& Cummins, M. (2017). NMC/CoSN horizon report: 2017 K. The New Media Consortium.

[42] González, C. S., Toledo, P., \& Muñoz, V. (2016). Enhancing the engagement of intelligent tutorial systems through personalization of gamification. International Journal of Engineering Education, 32(1), 532-541.

[43] Bergaus, M. (2015). Literature Review: ICT, SDPs and System Design for User Needs. In M. Bergaus (Ed.), Design Issues for Service Delivery Platforms (pp. 27-94). Springer Fachmedien Wiesbaden. https://doi.org/10.1007/978-3-658-10541-9_2

[44] Gonsalves, L., Campbell, A., Jensen, L., \& Straker, L. (2015). Children with developmental coordination disorder play active virtual reality games differently than children with typical development. Physical therapy, 95(3), 360-368.

[45] Bossavit, B., \& Pina, A. (2014, October). Designing educational tools, based on body interaction, for children with special needs who present different motor skills. In Interactive Technologies and Games (iTAG), 2014 International Conference on (pp. 63-70). IEEE.

[46] González-González, C. S., Noda, A., Bruno, A., Moreno, L., \& Muñoz, V. (2015). Learning subtraction and addition through digital boards: a Down syndrome case. Universal Access in the Information Society, 14(1), 29-44. https://doi.org/http://dx.doi.org/10.1007/s10209-013-0330-3

[47] Torres-Carrion, P., \& Gonzalez-Gonzalez, C. (2016). Personalization of classroom's digital resources with Gestural-Human Computer Interaction. Application to Children with Down Syndrome. In 11 Congreso Colombiano de Computación. Popayán-Colombia: IEEE Xplore Digital Library. 
[48] Lazar, J., Feng, J. H., \& Hochheiser, H. (2017). Research methods in human-computer interaction. Morgan Kaufmann. Pp 506-507.

[49] Kirk, S. A., McCarthy, J. J., \& Kirk, W. D. (2011). ITPA: test Illinois de aptitudes psicolingüísticas. Tea.

[50] Morgado, I. (2005). The psychobiology of learning and memory fundamentals and recent advances. Revista de Neurología, 40(5), 289-297. 